\title{
La limitación coercitiva del libre tránsito en México frente al Covid-19*
}

\begin{abstract}
Alan Jair García Flores**
RESUMEN: El presente artículo analiza la limitación coercitiva del ejercicio de libre tránsito en México que esgrimieran los Gobernadores de Michoacán, Jalisco y Yucatán mediante decretos o discurso punitivo sobre el tipo penal de peligro de contagio como medida para garantizar el resguardo domiciliario de su población en el marco de la pandemia Covid-19.

Con base en lo anterior, se abordan aspectos esenciales de las directrices de intervención sanitaria establecidas por el Consejo de Salubridad General (CSG) en México, al tiempo que se examinan los postulados normativos de restricción o suspensión de derechos humanos consagrados en la Constitución Federal y los tratados internacionales, particularmente del ejercicio de libre tránsito, en aras de determinar los requisitos formales $y$ materiales que deben acreditarse, así como los sujetos legitimados para proclamarlas.

Palabras clave: Covid-19, libre tránsito, limitación coercitiva, estado de excepción, siege. estado de sitio.

ABSTRACT: This article analyzes the coercive limitation of the exercise of free transit in Mexico used by the Governors of Michoacán, Jalisco and Yucatán through decrees or punitive discourse on the fellony of contagion danger as a measure to guarantee the home issolation of their population at the framework of the Covid19 pandemic.

Based on the above, essential aspects of the health intervention guidelines established by the General Health Council (GHC) in Mexico are addressed, while examining the regulatory postulates of restriction or suspension of human rights enshrined in the Federal Constitution and international treaties, particularly the exercise of free transit, in order to determine the formal and material requirements that must be accredited, as well as the legal entities to proclaim them. Keywords: Covid-19, free transit, coercive limitation, state of emergency, state of
\end{abstract}

SUMARIO: Introducción. 1. Prolegómeno de la pandemia Covid-19. 2. Reminiscencia constitucional de la limitación a la libertad de tránsito en México. 3. El ardid de la limitación

\footnotetext{
* Artículo recibido el 11 de mayo de 2020 y aceptado para su publicación el $1^{\circ}$ de junio de 2020.

** Docente de la facultad de Derecho e investigador del Centro de Estudios sobre Derecho, Globalización y Seguridad de la Universidad Veracruzana.
} 
coercitiva al ejercicio de libre tránsito en México como política sanitaria contra el Covid-19. Conclusiones. Fuentes de consulta.

\section{Introducción}

La pandemia Covid-19 constituye un desafío para el Estado mexicano, el cual debe esgrimir políticas públicas para afrontar este grave problema epidemiológico sin que medien determinaciones arbitrarias que se aparten del halo proteccionista de derechos humanos trazado por la Constitución Política de los Estados Unidos Mexicanos y los tratados internacionales.

Es por lo anterior que resulta indispensable estudiar el devenir de la pandemia a nivel internacional y su arribo a México para determinar las intervenciones de salubridad que adoptara el Gobierno Federal en coordinación con las autoridades locales y municipales.

En virtud de los métodos dogmático-jurídico, sistemático jurídico y análisis de contenido, se identifican las autoridades legitimadas para decretar la restricción o en su caso suspensión de la libertad de tránsito así como los requisitos de procedibilidad formales y materiales que deben cumplimentarse a la luz de las disposiciones constitucionales y del Derecho Internacional de los Derechos Humanos (DIDH) como punto de distinción entre los límites de esta prerrogativa y el establecimiento de un Estado de excepción consagrado por el numeral 29 de la Constitución Política de los Estados Unidos Mexicanos.

El fin ulterior del presente artículo reside en analizar la limitación coercitiva a la libertad de tránsito esgrimida por los Gobernadores de Michoacán, Jalisco y Yucatán mediante decretos o discursos punitivos como medio para garantizar el resguardo domiciliario de la población frente a la pandemia Covid-19, y su desajuste con las directrices emitidas por el CSG en México.

\section{Prolegómeno de la pandemia Covid-19}

El coronavirus fue advertido en la década de los 60's como miembro de la familia de virus que provocan enfermedades respiratorias que afecta a animales y humanos, aunque con cepas distintas que provocan el Síndrome Respiratorio Agudo Severo (SARS).

El 31 de diciembre de 2019, la Comisión Municipal de Salud de Wuhan, China notificó a la Organización Mundial de la Salud (OMS), el brote de casos de neumonía atípica ocasionada por el coronavirus 2 del Síndrome Respiratorio Agudo Severo (SARS-CoV-2) de probable origen zoonótico y que fuere causante de la enfermedad denominada Covid-19 (Organización Mundial de la Salud, 2020: s/p; Gobierno de México, 2020: 4).

Es dable destacar que la OMS ha precisado que la enfermedad se propaga mediante "gotículas despedidas de la nariz o la boca de una persona infectada al toser, estornudar o hablar [... y que pueden caer en objetos que a su vez estén en contacto con personas provocando su contagio]", por lo que cualquier persona puede contraer el coronavirus y desarrollar alguna enfermedad grave, en cuyo tenor, los síntomas de esta patología son: "Fiebre, tos seca y cansancio [...] dolores, congestión nasal, dolor de garganta o diarrea" (Organización Mundial de la Salud (a), 2020: s/p). 
La OMS informó en fecha 11 de marzo de 2020, que debido a las dimensiones del Covid19, éste alcanzó el nivel de pandemia (Organización Mundial de la Salud, 2020: s/p), misma que debe diferenciarse de una epidemia, debido a que aquélla se refiere a "la propagación mundial de una nueva enfermedad [...] y la mayoría de las personas no tienen inmunidad" (Organización Mundial de la Salud, 2010: s/p); mientras que la epidemia se avoca a "un aumento inusual del número de casos de una determinada enfermedad en una población específica, en un periodo de tiempo determinado" (Horcajada y Padilla, 2013: 182).

Amén de lo anterior, resulta prudente apuntalar que, al 30 de mayo de 2020, se registraron a nivel mundial un total de 5, 817, 385 casos confirmados de Covid-19, de los cuales son advertibles 362, 705 defunciones asociadas a esta enfermedad, correspondiente a una tasa global de letalidad de 6.2\% (Secretaría de Salud, 2020: 1). Asimismo, la cifra global de mérito se distribuye de la siguiente forma: América $(2,677,500)$; Europa $(2,122,350)$; Mediterráneo Oriental (489, 921); Asia Sudoriental (294, 525); Pacífico Oriental (181, 187); y, África $(96,902)$ (Secretaría de Salud, 2020: 1).

A partir de los precitados datos, el conteniente americano liderea el número de confirmados por Covid-19. Sin embargo, el caso de México requiere especial atención pues al 30 de mayo de 2020, se acumularon 87, 512 confirmados y 9, 779 defunciones atribuidas a este padecimiento (Secretaría de Salud, 2020: 2).

La experiencia internacional sobre el impacto del coronavirus permitió que el Gobierno de la República encabezado por el presidente Andrés Manuel López Obrador impulsara una serie de determinaciones para su abordaje, en cuya virtud, la Secretaría de Salud (SSA) dio a conocer que a partir de los tres escenarios de transmisión del Covid-19 emitidos por la OMS, se definían las siguientes fases de la epidemia en México:

\begin{tabular}{|l|l|}
\hline \multicolumn{1}{|c|}{ Escenario OMS } & \multicolumn{1}{|c|}{ Fases SS } \\
\hline $\begin{array}{l}\text { 1. Países con uno o más casos } \\
\text { importados o detectados localmente } \\
\text { (casos esporádicos) }\end{array}$ & $\begin{array}{l}\text { Fase 1: Esta fase corresponde únicamente } \\
\text { a casos importados, es decir, personas } \\
\text { que adquirieron el virus fuera del país. En } \\
\text { esta etapa el número de afectados es } \\
\text { reducido y los contactos de estos se } \\
\text { encuentran identificados. Medidas: } \\
\text { Aislamiento de los pacientes } \\
\text { diagnosticados, identificación de los } \\
\text { contactos, supervisión de las personas } \\
\text { contagiadas y seguimiento de las que } \\
\text { estuvieron en contacto con ellos. }\end{array}$ \\
\hline $\begin{array}{l}\text { 2. Países que experimentan casos } \\
\text { agrupados en el tiempo, ubicación } \\
\text { geográfica y/o exposición común } \\
\text { (grupos de casos) }\end{array}$ & $\begin{array}{l}\text { Fase 2: Contagios por transmisión local, } \\
\text { es decir, que adquirieron el virus por una } \\
\text { fuente dentro del país. El número de } \\
\text { afectados rebasa los cientos de casos. } \\
\text { Medidas: Se utiliza contención sanitaria } \\
\text { focalizada en las áreas donde se registra } \\
\text { la mayoría de los contagios y la }\end{array}$ \\
\hline
\end{tabular}




\begin{tabular}{|l|l|}
\hline & $\begin{array}{l}\text { suspensión de actividades dentro de } \\
\text { éstas. }\end{array}$ \\
\hline $\begin{array}{l}\text { 3. Países que experimentan grandes } \\
\text { brotes locales (transmisión } \\
\text { comunitaria) }\end{array}$ & $\begin{array}{l}\text { Fase 3: En esta etapa se registra una } \\
\text { propagación extensa y miles de personas } \\
\text { resultan afectadas por el virus. Las } \\
\text { cadenas de propagación resultan difíciles } \\
\text { de romper, lo cual requiere de estrategias } \\
\text { más drásticas. } \\
\text { Medidas: Las actividades masivas y } \\
\text { escolares deben ser suspendidas. }\end{array}$ \\
\hline
\end{tabular}

(Martínez, Torres y Orozco, 2020: 8-9).

Con base en lo preceptuado por la SSA se advirtió que el primer caso confirmado de Covid-19 en México en fecha 27 de febrero de 2020 -correspondiente a la fase 1-, se debió a una importación ya que se trató de un masculino de 35 años de la Ciudad de México con antecedentes de viaje a Italia (Comité Nacional para la Vigilancia Epidemiológica, 2020: 2).

Así las cosas, el 14 de marzo de 2020 se dio a conocer que el número de casos confirmados por Covid-19 ascendía a 41 personas (Secretaría de Salud (a), 2020: 2), en cuyo tenor, Esteban Moctezuma, Secretario de Educación Pública informó que las clases presenciales en todos los niveles educativos se suspendían del 23 de marzo al 17 de abril de 2020 (Secretaría de Educación Pública, 2020: s/p).

Habida cuenta de lo anterior, el Estado mexicano reconoció en fecha 24 de marzo de 2020 que se encontraba en fase 2, misma que previamente había sido determinada por la OMS (Consejo General del Instituto Nacional Electoral, 2020: s/p) y en consecuencia, emitió a través de la SSA el acuerdo por el que precisan dos aspectos fundamentales: el reconocimiento que hiciera el CSG de "la epidemia de enfermedad por el virus SARS-CoV2 (COVID-19) en México como una enfermedad grave de atención prioritaria" en fecha 19 de marzo de 2020; y, el establecimiento de medidas preventivas "[... a] implementar para la mitigación y control de los riesgos para la salud que implica [esta enfermedad]" (Secretaría de Salud (b), 2020: s/p).

El supra mencionado acuerdo de la SSA puntualizó aspectos esenciales que deben tener presente tanto autoridades como gobernados ya que proclama que, por ministerio de la Ley General de Salud, es precisamente la SSA a quien le compete elaborar y realizar en coordinación con instituciones del sector salud y los gobiernos estatales los programas o campañas temporales o permanentes para el control o erradicación como el Covid-19, toda vez que:

[...] en caso de epidemia de carácter grave, peligro de invasión de enfermedades transmisibles, situaciones de emergencia o catástrofe que afecten al país, la dependencia que se refiere el considerando anterior dictará inmediatamente las medidas indispensables para prevenir y combatir los daños a la salud, a reserva de que tales medidas sean después sancionadas por el Presidente de la República. (Secretaría de Salud (b), 2020: s/p)

En este sentido, el acuerdo en referato especifica que las medidas indispensables para prevenir, controlar o erradicar el Covid-19 deben ser dictadas por la SSA a reserva de ser 


\section{García A. / La limitación coercitiva del libre tránsito en México frente al Covid-19}

sancionadas por el titular del Ejecutivo Federal y que, a su vez, los gobiernos estatales trabajarán en coordinación con aquélla, sin que esto implique la adopción de medidas fuera de su esfera competencial.

De tal guisa, el artículo primero del acuerdo de marras señala que las medidas preventivas contra el Covid-19 se encuentran definidas por la Jornada Nacional de Sana Distancia cuyo objetivo estriba en:

[...] El distanciamiento social para la mitigación de la transmisión poblacional de virus SARS-CoV2 (COVID-19), disminuyendo así el número de contagios de persona a persona y por ende el de propagación de la enfermedad, con especial énfasis en grupos vulnerables, permitiendo además que la carga de enfermedad esperada no se concentre en unidades de tiempo reducidas, con el subsecuente beneficio de garantizar el acceso a la atención médica hospitalaria para los casos graves. (Secretaría de Salud (b), 2020: s/p)

El fin ulterior de las medidas preventivas favorece la idea del distanciamiento social como vía para disminuir los contagios por Covid-19, sin que medie adopción de un Estado de excepción, circunstancia que se reafirma en el artículo segundo de este acuerdo, a saber:

* Evitar la asistencia a centros de trabajo, espacios públicos y otros lugares concurridos, a los adultos mayores de 65 años o más y grupos de personas con riesgo a desarrollar enfermedad grave y/o a morir a causa de ella.

* Suspensión temporal de las actividades escolares en todos los niveles educativos.

* Suspensión temporal de las actividades de los sectores público, social y privado que involucren la concentración física, tránsito o desplazamiento de personas.

* Suspensión temporal de eventos masivos, reuniones y congregaciones de más de 100 personas.

* Cumplir con las medidas básicas de higiene.

* Las demás que en su momento se determinen necesarias por la Secretaría de Salud y que serán informadas a la población en general. (Secretaría de Salud (b), 2020: s/p)

Siguiendo este hilo de pensamiento, es dable reconocer que entre las acciones de prevención que hasta ahora se han publicado por parte de la SSA no se aprecia la restricción al libre tránsito bajo amenaza de imponer pena corporal de prisión, ya que, solo la última medida deja abierta la posibilidad de establecer determinaciones adicionales a las enunciadas, las cuales deben ser dadas a conocer.

En esta tesitura, es menester recordar que en fecha 21 de abril de 2020, el Subsecretario de Prevención y Promoción de la Salud, Hugo López Gatell informó que el CSG había aprobado el inicio de la fase 3 en México, hecho que representaba "la existencia de brotes activos y propagación en el territorio con más de mil casos" (Secretaría de Salud (c), 2020: $s / p)$.

Entre las acciones estatales que implicaba la fase 3 de Covid-19 se aprecia la extensión de la Jornada Nacional de Sana Distancia hasta el 30 de mayo de 2020 y, en consecuencia, la ampliación de la suspensión de actividades que no fueran esenciales para el Gobierno de la República.

El Subsecretario de Prevención y Promoción de la Salud sentenció que las medidas que empleen las entidades federativas no pueden ser más laxas que las proclamadas por la autoridad federal, ya que su trabajo es precisamente, hacer cumplir lo dictado por la SSA (Secretaría de Salud (c), 2020: s/p). 
Así las cosas, el 14 de mayo de 2020, la SSA publicó en el Diario Oficial de la Federación el acuerdo que estableció la estrategia para la reapertura gradual, ordenada y cauta de las actividades sociales, educativas y económicas; y, un sistema de semáforo por regiones estructurado en cuatro colores: rojo (permite actividades económicas esenciales); naranja (admite aforo reducido de actividades de espacio público en lugar abierto, así como actividades esenciales y no esenciales con operación reducida); amarillo (acepta aforo permitido de actividades de espacio público en lugar abierto y cerrado siendo este último con restricciones; $y$, consiente todas las actividades económicas); $y$, verde (no restringe escuelas, espacio público y actividades económicas generales), el cual iniciaría el 1 de junio de 2020 y evaluaría semanalmente el riesgo epidemiológico relacionado con la reapertura de actividades en cada entidad federativa (Secretaría de Salud (d), 2020: s/p).

Lo anterior sentará las bases de la estrategia general de nueva normalidad que permitirá un retorno o la continuidad de las actividades laborales seguro, escalonado y responsable, a partir de la observancia de etapas, donde la primera incluiría a los municipios de la esperanza donde no tuvieran contagios reportados ni vecindad con municipios con contagios -inició el 18 de mayo de 2020-; la segunda abarcaría la ampliación de las actividades esenciales hacia a la minería, transporte y construcción; y, por otro lado, la emisión de los Lineamientos Técnicos de Seguridad Sanitaria en el Entorno Laboral para la reactivación temprana de estos sectores -contemplaría del 18 al 31 de mayo de 2020-; y, la tercera versaría sobre la reapertura socioeconómica, a través de un sistema de semáforo de riesgo epidemiológico semanal por regiones -comenzaría el 1 de junio de 2020(Secretaría de Salud (e), 2020: s/p).

Llegado este punto, se infiere que la política nacional sanitaria de prevención contra la pandemia del Covid-19 encabezada por el Gobierno Federal no propone la adopción de un Estado de excepción caracterizado por la suspensión de derechos fundamentales sino que apuesta por la concientización de los gobernados para ser responsables y acatar las medidas en el ámbito de sus características individuales en aras de mitigar los efectos de este fenómeno viral que día a día causa estragos a nivel mundial.

\section{Reminiscencia constitucional de la limitación a la libertad de tránsito en México}

El Estado mexicano ha enfrentado grandes desafíos que poco a poco permitieron el reconocimiento de prerrogativas inherentes a la persona humana, en cuyo caso, es prudente recordar que debido a la reforma al artículo 1 de la Constitución Política de los Estados Unidos Mexicanos, los derechos humanos se positivizaron erigiéndose en derechos fundamentales:

En los Estados Unidos Mexicanos todas las personas gozarán de los derechos humanos reconocidos en esta Constitución y en los tratados internacionales de los que el Estado Mexicano sea parte, así como de las garantías para su protección, cuyo ejercicio no podrá restringirse ni suspenderse, salvo en los casos y bajo las condiciones que esta Constitución establece.

[...]

Todas las autoridades, en el ámbito de sus competencias, tienen la obligación de promover, respetar, proteger y garantizar los derechos humanos de conformidad con los principios de universalidad, 
interdependencia, indivisibilidad y progresividad. En consecuencia, el Estado deberá prevenir, investigar, sancionar y reparar las violaciones a los derechos humanos, en los términos que establezca la ley. (Art. 1 de la Constitución Política de los Estados Unidos Mexicanos)

Las autoridades del Estado mexicano al tenor de sus ámbitos competenciales tienen la obligación de proteger, respetar, promover y garantizar los derechos fundamentales, cuyo ejercicio solo puede ser restringido o suspendido de acuerdo con lo estipulado por la propia Constitución Federal.

No obstante, es dable sostener que el ejercicio de los derechos fundamentales como la libertad de tránsito puede ser objeto de restricción o suspensión siempre que se actualicen los supuestos normativos plasmados en la propia Ley Suprema (Human Right Watch, 2020: $s / p)$, situación que también se encuentra prevista en el DIDH, pero que en definitiva, no debe prestarse a confusiones entre los límites de ciertas prerrogativas y la restricción o suspensión del ejercicio de derechos previsto en el artículo 29 de la Constitución Federal.

Hecha esta salvedad es menester referir que la protección de derechos fundamentales constituye un aspecto esencial en un Estado de Derecho, sin demeritar que, ante amenazas graves, se deban hacer valer sus límites normativos previamente establecidos en aras de salvaguardar otros.

Lo dicho hasta aquí permite considerar que la salud es un derecho de vital importancia en el ámbito constitucional e internacional, pues se traduce en una obligación irreductible para los Estados:

* Toda persona tiene derecho a la protección de la salud. La Ley definirá las bases y modalidades para el acceso a los servicios de salud y establecerá la concurrencia de la Federación y las entidades federativas en materia de salubridad general, conforme a lo que dispone la fracción XVI del artículo 73 de esta Constitución (Art. 4 de la Constitución Política de los Estados Unidos Mexicanos).

* Toda persona tiene derecho a un nivel de vida adecuado que le asegure, así como a su familia, la salud y el bienestar (Art. 25.1 de la Declaración Universal de los Derechos Humanos).

* Los Estados Partes en el presente Pacto reconocen el derecho de toda persona al disfrute del más alto nivel posible de salud física y mental (Art. 12.1 del Pacto Internacional de Derechos Económicos, Sociales y Culturales).

* Toda persona tiene derecho a la salud, entendida como el disfrute del más alto nivel de bienestar físico, mental y social. [...] Con el fin de hacer efectivo el derecho a la salud los Estados Partes se comprometen a reconocer la salud como un bien público (Art. 10, párrs. 1 y 2 del Protocolo adicional a la Convención Americana sobre Derechos Humanos en materia de Derechos Económicos, Sociales y Culturales "Protocolo de San Salvador").

En este sentido, se aprecia que la salud además de considerarse como una prerrogativa del gobernado debe ser tratada como un bien público que requiere la generación de políticas públicas que garanticen a cualquier persona el más alto nivel de disfrute.

Avanzando con nuestro razonamiento, se advierte que algunos derechos reconocidos por la Ley Suprema del Estado mexicano tienen parámetros delimitadores que los rigen, verbigracia, la libertad de tránsito, misma que estriba en:

Toda persona tiene derecho para entrar en la República, salir de ella, viajar por su territorio y mudar de residencia, sin necesidad de carta de seguridad, pasaporte, salvoconducto u otros requisitos semejantes. El ejercicio de este derecho estará subordinado a las facultades de la autoridad judicial, en los casos de responsabilidad criminal o civil, y a las de la autoridad administrativa, por lo que toca a 
las limitaciones que impongan las leyes sobre emigración, inmigración y salubridad general de la República, o sobre extranjeros perniciosos residentes en el país. (Art. 11 de la Constitución Política de los Estados Unidos Mexicanos)

De tal suerte, la libertad de tránsito del gobernado en el territorio mexicano no media exigencia de requisitos como pasaporte, salvoconductos o cartas de seguridad, sin embargo, ello no implica que sea absoluto sino por el contrario, se prevé la subordinación de su ejercicio a las atribuciones de las autoridades judiciales y administrativas siendo estas últimas de vital importancia pues refiere limitaciones sobre leyes de salubridad general.

En consonancia con lo anterior, la interpretación constitucional aquí planteada requiere considerar el texto del artículo 11 en correlación con la redacción del numeral 73 fracción $\mathrm{XVI}$ del cuerpo legal en referato:

Artículo 73. El Congreso tiene facultad:

$[\ldots]$

XVI. Para dictar leyes sobre nacionalidad, condición jurídica de los extranjeros, ciudadanía, naturalización, colonización, emigración e inmigración y salubridad general de la República.

1a. El Consejo de Salubridad General dependerá directamente del Presidente de la República, sin intervención de ninguna Secretaría de Estado, y sus disposiciones generales serán obligatorias en el país.

2a. En caso de epidemias de carácter grave o peligro de invasión de enfermedades exóticas en el país, la Secretaría de Salud tendrá obligación de dictar inmediatamente las medidas preventivas indispensables, a reserva de ser después sancionadas por el Presidente de la República.

3a. La autoridad sanitaria será ejecutiva y sus disposiciones serán obedecidas por las autoridades administrativas del País.

La redacción del texto constitucional en estudio refiere una serie de aspectos que no pueden pasarse por alto:

* La única autoridad a la que se subordina el CSG es el Presidente de la República.

* Las disposiciones generales que emita el CSG son obligatorias.

* Ante la existencia de epidemias graves o peligro de invasión de enfermedades exóticas corresponde obligatoriamente a la SSA la emisión de medidas de prevención que deben ser sancionadas por el Presidente de la República.

* Las autoridades administrativas del país deben acatar las disposiciones emitidas por el CSG.

Bajo esta óptica se aprecia que, por ministerio de ley, las determinaciones dictadas por el CSG se erigen como obligatorias y, por lo tanto, deben ser obedecidas por las autoridades administrativas, quienes no pueden implementar medidas más laxas ni, por el contrario, invadir esferas competenciales al implementar acciones más rigurosas que las dictadas por los sujetos legitimados constitucionalmente para tal efecto.

En este orden de ideas, el DIDH prevé la restricción de la libertad de tránsito al tenor de puntuales supuestos:

* El artículo 22.3 de la Convención Americana sobre Derechos Humanos estipula que el ejercicio del derecho de circulación y residencia puede ser restringido 
siempre que exista una ley que la regule y el fin ulterior estribe en proteger, entre otros, a la salud pública.

* El numeral 12.3 del Pacto Internacional de Derechos Civiles y Políticos proclama que la libertad de circulación, residencia y migración solo será objeto de restricción cuando se estipule en la ley, sea necesaria para proteger la salud y a su vez, compatible con los demás derechos reconocidos en el mismo pacto.

* El arábigo 4 del Pacto Internacional de Derechos Económicos, Sociales y Culturales señala que el ejercicio de los derechos solo puede someterse a las limitaciones que estipule la ley en la medida compatible con la naturaleza de esas prerrogativas siempre que se promueva el bienestar general en una sociedad democrática.

* La cláusula 15 de los Principios de Siracusa sobre las disposiciones de limitación y derogación del Pacto Internacional de Derechos Civiles y Políticos "Salud Pública" constituye una razón para la procedencia de ciertos derechos en aras de permitir a un Estado esgrimir medidas para atender una grave amenaza a la salud de la población o de alguno de sus miembros.

Los instrumentos internacionales en referencia aluden a la procedencia de la restricción del ejercicio de derechos siempre que sea legitimada por la ley y obedezca a garantizar la protección de otras prerrogativas, entre ellas, la salud.

Sin embargo, no debe pasarse por alto que, de llegarse a decretar un Estado de excepción, dicha determinación deberá colmar los principios generales sobre su imposición y aplicación, verbigracia, estar sometida a principios jurídicos de aplicación general; ser de buena fe, al tenor de una evaluación objetiva de la situación, a fin de determinar el grado de amenaza a la vida de la nación; atender una interpretación restrictiva sobre las disposiciones del pacto que lo permite; sometimiento irrestricto al imperio de la ley; subordinación de todos los procedimientos a los objetivos básicos de los derechos humanos; proscripción de la inobservancia general de las obligaciones internacionales (Principios de Siracusa sobre las disposiciones de limitación y derogación del Pacto Internacional de Derechos Civiles y Políticos, 1984: s/p), es decir, que la autoridad legitimada para tomar esta decisión deberá justificar su proceder en una evaluación puntual y objetiva de la magnitud de la situación que se enfrenta, así como el impacto en poblaciones específicas o grupos marginados.

Habiendo abordado la limitación constitucional al ejercicio del derecho de libre tránsito, es menester distinguirlo de los supuestos jurídicos tendientes a la restricción y suspensión de derechos fundamentales consagradas en el numeral 29 de la Ley Suprema, en cuyo tenor, resulta esencial puntualizar que el presente estudio no tiene como fin analizar a fondo la figura jurídica de Estado de excepción.

De tal suerte, la Constitución Política de los Estados Unidos Mexicanos proclama a través de su numeral 29, que el ejercicio de los derechos puede restringirse o suspenderse, circunstancia que hace latente la presencia de un Estado de excepción que en ocasiones se asimila incorrectamente con un Estado de sitio. 
El Estado de sitio tuvo su origen en el Derecho Público Frances, a través de la Asamblea de 1791, en la cual, se utilizó el término état siége que preceptuaba el sometimiento constitucional de las autoridades y la población civil frente a las autoridades marciales, en cuya virtud, se infiere que el objetivo esencial reside en la suspensión de la libertad personal y sus garantías que favorecieran la detención y el traslado obligado de los individuos durante los conflictos de guerra (Salazar, 2013: 234).

Por su parte, la figura de Estado de excepción se atribuye a la "adquisición de un predomino temporal del Poder Ejecutivo sobre los otros poderes donde adquiere potestades especiales que no posee en una normalidad constitucional" (Salazar, 2013: 231).

De forma semejante, la Corte Interamericana de Derechos Humanos ha señalado que la suspensión de garantías no debe desvincularse de un escenario de democracia representativa ni mucho menos advertirse en sentido absoluto:

18. [...] no se trata de una 'suspensión de garantías' en sentido absoluto, ni de la 'suspensión de los derechos' ya que siendo éstos consustanciales con la persona lo único que podría suspenderse o impedirse sería su pleno y efectivo ejercicio.

20. [...] la Corte debe subrayar que, dentro de los principios que informan el sistema interamericano, la suspensión de garantías no puede desvincularse del 'ejercicio efectivo de la democracia representativa' a que alude el artículo 3 de la Carta de la OEA. [...] La suspensión de garantías carece de toda legitimidad cuando se utiliza para atentar contra el sistema democrático, que dispone límites infranqueables en cuanto a la vigencia constante de ciertos derechos esenciales de la persona. (CIDH, 1987: 7)

Ante lo esgrimido es dable señalar que la titularidad de derechos no es susceptible de ser restringida o suspendida pues las prerrogativas son inherentes a la persona por su sola condición humana, por tanto, lo único que puede resentir dicha afectación es el ejercicio del propio derecho.

Amén de lo anterior, resulta advertible que la restricción o suspensión del ejercicio de derechos determinada en el numeral 29 de la Constitución Federal no corresponde a un Estado de sitio ya que no se prevé la subordinación de las autoridades civiles y gobernados ante las autoridades marciales, sino por el contrario, se circunscribe a los siguientes puntos:

* Los supuestos que la motivan son la invasión, perturbación grave de la paz pública o de cualquier otro que ponga a la sociedad en peligro o conflicto.

* La única autoridad que podrá restringir o suspender en todo el país o área geográfica con aprobación del Congreso de la Unión o la Comisión Permanente cuando éste no se encuentre reunido es el Presidente de la República.

* La restricción o suspensión del ejercicio de derechos y garantías solo recaerá en aquéllas que constituyan un obstáculo para hacer frente, rápida y fácilmente a la situación que la motivó.

* La restricción o suspensión del ejercicio de derechos debe hacerse por un tiempo determinado, mediante prevenciones generales y sin que se contraiga a una determinada persona.

* Hallándose reunido el Congreso de la Unión concederá las autorizaciones necesarias para que el Ejecutivo Federal enfrente la situación, sin embargo, si aquél se 
encuentra en receso se le convocará inmediatamente para que acuerde lo procedente.

* La restricción o suspensión del ejercicio de derechos debe estar fundada y motivada en los términos de la Constitución Federal, sin perjuicio de ser proporcional al peligro enfrentado.

* En todo momento se deben observar los principios de legalidad, racionalidad, proclamación, publicidad y no discriminación.

* No podrá restringirse ni suspenderse el ejercicio de los derechos a la no discriminación, al reconocimiento de la personalidad jurídica, a la vida, a la integridad personal, a la protección a la familia, al nombre, a la nacionalidad; los derechos de la niñez; los derechos políticos; las libertades de pensamiento, conciencia y de profesar creencia religiosa alguna; el principio de legalidad y retroactividad; la prohibición de la pena de muerte; la prohibición de la esclavitud y la servidumbre; la prohibición de la desaparición forzada y la tortura; ni las garantías judiciales indispensables para la protección de tales derechos.

* La restricción o suspensión del ejercicio de derecho finalizará si se vence el plazo o lo decreta el Congreso de la Unión, sin que el Ejecutivo Federal pueda hacer observaciones a este último.

* Durante la restricción o suspensión del ejercicio de derechos será la Suprema Corte de Justicia de la Nación la que revise y se pronuncie con inmediatez sobre los decretos que emita el Ejecutivo Federal (Art. 29 de la Constitución Política de los Estados Unidos Mexicanos).

El artículo 29 constitucional ofrece aspectos medulares sobre el procedimiento a seguir para que pueda restringirse (limitarse parcialmente los derechos sin llegar a la suspensión total), o suspenderse (vedarse totalmente los derechos con excepción de los prohibidos constitucionalmente), lo cual implica que el Presidente de la República con aprobación del Congreso de la Unión sea quien lo esgrima, sin dejar de lado, que la Suprema Corte de Justicia de la Nación deberá analizar la constitucionalidad de los decretos que se emitan durante ese periodo, motivo por el que se avista que hasta el momento, no es posible hablar de un Estado de excepción con motivo de la pandemia Covid-19, ya que no se han actualizado los supuestos jurídicos de mérito.

\section{El ardid de la limitación coercitiva al ejercicio de libre tránsito en México como política sanitaria contra el Covid-19}

El Estado como garante de los derechos fundamentales de los gobernados debe esgrimir acciones tendientes a proteger la convivencia humana sin rebasar los límites establecidos en su Constitución Federal y los instrumentos jurídicos inherentes al DIDH. De tal suerte, en el marco de la pandemia por Covid-19 en México, el CSG es la única autoridad legitimada para limitar el ejercicio del derecho al libre tránsito, circunstancia que previamente se distinguió del procedimiento inherente al artículo 29 de la Constitución Política de los Estados Unidos Mexicanos. 
Amén de lo anterior, el artículo 30 de la Convención Americana sobre Derechos Humanos ha sostenido que la restricción o suspensión de derechos humanos requiere de la acreditación de ciertos requisitos entre los que destacan: la aplicación basada en la ley con límites establecidos; la búsqueda del interés general; $y$, el pleno ajuste con el propósito de su emisión.

Así las cosas, la Subsecretaría de Derechos Humanos, Población y Migración (SDHPM) dependiente de la Secretaría de Gobernación ha puntualizado que:

Si bien la reducción de la movilidad de las personas es el objetivo prioritario de la Jornada Nacional de Sana Distancia, imponer la obligatoriedad del resguardo domiciliario mediante el uso de la fuerza pública es una medida lesiva, desproporcional, puede ocasionar abusos de autoridad y no corresponde al objetivo de salvaguardar la salud pública. Además, según la distribución de competencias, únicamente puede dictarla el Consejo de Salubridad General, no los estados o municipios. (2020:4)

En este mismo orden de ideas, es dable inferir que la política nacional sanitaria contra el Covid-19 no ha incorporado el uso de la fuerza pública como mecanismo para asegurar el resguardo domiciliario y, por el contrario, apostó por la concientización de la población para evitar una mayor exposición a este virus.

Por su parte, resulta destacable la postura de la Suprema Corte de Justicia de la Nación sobre la necesidad de cumplimentar los requisitos de naturaleza formal y material que validen la restricción o en su caso, la suspensión del ejercicio de derechos humanos como la libertad de tránsito, a saber:

* Formales:

- Establecimiento de las medidas en una ley formal y material (principio de reserva de ley) que persiga el interés general o público.

$\circ \quad$ Se garantice los derechos de igualdad y seguridad jurídica.

* Material:

○ $\quad$ Se supere un test de proporcionalidad en que se verifique:

- La necesidad de las medidas.

- Persecución de un interés o finalidad constitucionalmente legítima.

- Las medidas sean razonables y ponderables en el marco de una sociedad democrática. (Suprema Corte de Justicia de la Nación, 2013: 557)

En atención a lo dispuesto por el Máximo Tribunal Constitucional es dable considerar que, si bien la Ley Fundamental y los tratados internacionales en materia de derechos humanos reconocen que la protección de la salud se privilegia sobre la libertad de tránsito, ello no implica que la necesidad de las medidas de limitación coercitiva sobre el ejercicio de esta prerrogativa para garantizar el resguardo domiciliario proclamado por las autoridades locales sea razonable y ponderable ya que resultan más restrictivas que las directrices esgrimidas por el CSG -las cuales son obligatorias para todas las autoridades administrativas del país-, quien por ministerio del artículo 73, fracción XVI de la Constitución Política de los Estados Unidos Mexicanos, se erige como la autoridad legitimada para emitir una restricción sobre el derecho de mérito -previa sanción del Ejecutivo Federal-.

Por su parte, el Subsecretario de Prevención y Promoción de la Salud, Hugo López Gatell, ha declarado que las medidas de intervención de salud pública en México no involucran la 


\section{García A. / La limitación coercitiva del libre tránsito en México frente al Covid-19}

coerción a las personas en su individualidad como vía de acato al llamado de la Jornada Nacional de Sana Distancia:

[...] De acuerdo lo que ocurrió en los países europeos en donde usó la fuerza pública como un mecanismo de coerción para inducir a que los ciudadanos se quedaran en casa, desde el principio nos pareció inconveniente en México, lo hemos dicho, lo seguimos diciendo, aun en este momento de mayor transmisión, no tenemos plan alguno de militarizar la respuesta de salud pública, no se va a implantar toques de queda, estados de excepción ni se va a usar la fuerza pública como mecanismos de coerción.

Las intervenciones de salud pública que diseñó el Gobierno de México fueron cuidadosamente analizadas para que restringieran las actividades que hacen que las personas salgan de casa.

Una persona en general puede salir por muchas razones de la casa, pero hay tres que son las principales: trabajo, escuela o recreación. (Presidencia de la República, 2020: s/p)

Bajo esta tesitura, las autoridades estatales y municipales deben alinear sus acciones a las medidas de intervención de salud pública dictadas por el CSG ya que, de acuerdo con la distribución de competencias, aquellas no están legitimadas para decretar medidas más restrictivas sobre el ejercicio de la libertad de tránsito como el uso de fuerza pública para garantizar el resguardo domiciliario.

Con base en lo anterior, se infiere que el ejercicio de libre tránsito puede restringirse siempre que sea dictado por las autoridades legitimadas constitucionalmente y "se comprueben debidamente los motivos en que se funda la restricción" (Suprema Corte de Justicia de la Nación (a), 1924: 111), en cuya virtud, la autoridad local no es competente para emitir determinaciones de esta naturaleza puesto que:

[...] las medidas impuestas con el uso de la fuerza no cumplen con los requisitos de proporcionalidad, propician actos de abuso de autoridad y pueden tener efectos graves sobre el abasto de alimentos y medicinas; el acceso a servicios públicos, como seguridad y saneamiento, y en las cadenas de suministros de insumos esenciales de salud. (Subsecretaria de Derechos Humanos, Población y Migración, 2020: 4)

Al respecto, el numeral 11.2 de la Declaración Universal de los Derechos Humanos señala que el principio de legalidad es la base de la imputación penal, sin embargo, las autoridades deben estar legitimadas para determinar la imposición de sanciones frente a conductas que sean antijurídicas y en última instancia, delictivas.

Habría que decir también que la SDHPM refirió que diversos gobiernos estatales y municipales implementaron una serie de medidas que se extralimitan a las proclamadas por el CSG, entre las que se encuentran:

El establecimiento de un mal llamado 'Toque de queda' en al menos 31 municipios de 11 estados al 22 de abril: Guerrero, Michoacán, Quintana Roo, Yucatán, Jalisco, Baja California, Sonora, Chihuahua, Morelos, Coahuila y Nuevo León.

El gobierno del estado de Sonora anunció desde el 13 de abril el programa 'Quédate en casa obligatorio fase 2', como acuerdo del Consejo Estatal de Salud, imponiendo multas a las personas por incumplir el confinamiento obligatorio y facultando a las corporaciones policiales a arrestar con uso de la fuerza pública a las personas. Además, 11 municipios del estado han decretado 'toque de queda' en distintos horarios.

Los gobiernos de Michoacán y Jalisco decretaron el aislamiento obligatorio, señalando sanciones como multas, arrestos y trabajo comunitario a la persona que lo incumpla, lo que puede llevar al uso desmedido y arbitrario de la fuerza pública. (2020: 4) 
De acuerdo con la teoría relativa o utilitarista de la pena en su dimensión de prevención general negativa, se aprecia que la intimidación es una forma en que el Estado evita que la población cometa alguna conducta delictiva, situación que va de la mano con la idea del control como función principal del Derecho Penal (Contreras, 2011: 36), sin embargo, no debe olvidarse que toda acción vertida por la autoridad debe basarse en el principio de legalidad.

Entre las medidas de prevención esgrimidas por las autoridades estatales y municipales registradas por la SDHPM, sobresalen las relativas a Jalisco, Michoacán y Yucatán.

Así las cosas, la imposición de medidas de prevención sanitaria como el resguardo domiciliario obligatorio para "personas mayores de 60 años, mujeres embarazadas, con puerperio inmediato, personas con padecimientos de hipertensión arterial, diabetes mellitus, enfermedades cardiacas o pulmonar crónica, inmunosupresión, o insuficiencia renal o hepática" (Gobierno del Estado de Jalisco, 2020: 5), que involucran sanciones administrativas como la privación de la libertad mediante arresto de hasta treinta y seis horas (Gobierno del Estado de Jalisco, 2020: 4); o bien, el "arresto de hasta treinta y seis horas sin opción de permuta a trabajo comunitario" (Gobierno Constitucional del Estado de Michoacán de Ocampo, 2020: 4) que prevé el Estado de Michoacán a quien incumpla o se resista a las órdenes de la autoridad competente dictadas mediante decreto que declara el aislamiento obligatorio constituyen una invasión de esferas competenciales con la Federación y en consecuencia, involucran un desajuste con las directrices impulsadas por la autoridad legitimada constitucionalmente para atender la actual pandemia de coronavirus.

Aunado a lo esgrimido, puede destacarse el abordaje de prevención de Covid-19 en Yucatán, toda vez que sin miramientos el Gobernador de dicha entidad federativa, Mauricio Vila declaró vía Twitter que:

No permitiremos que la salud de la población yucateca se ponga en riesgo, es por eso que a la persona que presente los síntomas o haya sido diagnosticada con el Coronavirus y no acate las medidas de aislamiento para evitar el contagio, se le podrá imponer un castigo ... (1/2). (Vila, 2020: s/p)

$[\ldots]$

de hasta 3 años de cárcel y además podrá ser acreedora a una multa de hasta $\$ 86,800$. Esto bajo las sanciones que contemplan el Código Penal y La Ley de Salud de \#Yucatán. iPrevenir es tarea de todos! \#QuédateEnCasa \#UnidosComoUnoSolo (2/2). (Vila (a), 2020: s/p)

El posicionamiento estatal refiere la imposición de sanciones a quienes no acaten el resguardo domiciliario y presenten síntomas o hayan sido diagnosticadas con Covid-19, circunstancia que se antoja delicada en virtud, del señalamiento intimidatorio a quienes presenten síntomas aun sin poseer un resultado clínico que confirme el padecimiento de mérito.

Hecha esta salvedad, es pertinente invocar el tipo penal de peligro de contagio consagrado en el numeral 189 del Código Penal de Yucatán:

A quien sabiendo que está enfermo de un mal venéreo o de alguna enfermedad grave, transmisible en período infectante y de manera dolosa tenga cópula o por cualquier otro medio directo ponga en peligro de contagio la salud de otras personas, se le impondrá prisión de tres meses a tres años y además podrá ser recluido en un hospital. 
De acuerdo con la clasificación de daño que causa este tipo penal se puede ubicar en la categoría de peligro, ya que la conducta del agente coloca en riesgo al bien jurídico tutelado, aunque no cause lesión.

Asimismo, se destacan los siguientes aspectos del tipo penal de mérito: (I) Elemento subjetivo específico "sabiendo que está enfermo de un mal venéreo o de alguna enfermedad grave", ya que implica tener el conocimiento concreto de padecer una enfermedad de tal naturaleza; (II) Existencia de un periodo infectante de transmisión; (III) La forma o medio de ejecución será a través de "cópula o cualquier otro medio directo"; y, (IV) El núcleo del tipo estriba en poner "en peligro de contagio la salud de otras personas".

La existencia de resultados clínicos para detectar la presencia de Covid-19 en el organismo de las personas constituye un presupuesto necesario que concatenado con los demás elementos objetivos y subjetivos del tipo penal de peligro de contagio permitirían la actualización de la conducta punible, a fin de imponer sanciones, sin embargo, el hecho de emitir un mensaje como autoridad estatal tendiente a fomentar la coacción como vía para garantizar el resguardo domiciliario de quienes presenten síntomas evidencia acciones gubernamentales que exceden las directrices marcadas por el CSG, quien por disposición constitucional, se encuentra legitimado para dictar las medidas obligatorias a las que deben ceñirse las autoridades administrativas del país.

En consonancia con lo anterior, Amnistía Internacional sostiene que "las medidas de corte coercitivo suelen afectar de forma desproporcionada a comunidades que viven en la pobreza y a colectivos marginados o con riesgo de sufrir discriminación" (Guevara, 2020: $s / p)$, en razón de lo cual, es dable recordar que el Estado mexicano tiene una marcada pluralidad de condiciones socioeconómicas que provocan la inviabilidad de la aplicación de medidas extremas como el empleo del Derecho Penal para prevenir o controlar contagios en la población, sin dejar de lado, la invasión de atribuciones en que incurren las autoridades estatales y municipales al decretar acciones que constitucionalmente corresponden al CSG o en su caso, al Presidente de la República.

\section{Conclusiones}

La pandemia de Covid-19 representa un desafío para la comunidad mundial pues implica la toma de decisiones por parte de los Estados para afrontar esta amenaza, sin embargo, deben destacarse las pautas normativas que engarzan la protección del derecho humano a la salud para evitar la implementación de acciones arbitrarias que adolezcan de un sustento jurídico a nivel nacional e internacional.

Habida cuenta de lo anterior, se aprecia que el ejercicio de los derechos humanos solo puede ser suspendido o restringido por la autoridad legitimada por ministerio de ley para tal efecto y que, a su vez, existen casos puntuales como el libre tránsito que tienen un límite de acuerdo con la Constitución Política de los Estados Unidos Mexicanos y el DIDH.

EI CSG impulsó la Jornada Nacional de Sana Distancia como política sanitaria contra el Covid-19, en la que, instruyen las directrices de intervención pública a las autoridades estatales y municipales, a fin de que coadyuven sin exceder su ámbito competencial, no obstante, es dable advertir que éstas han implementado acciones más restrictivas en su 
afán de consolidar una estrategia de prevención epidemiológica, entre las que sobresale, el uso de la coerción para garantizar el resguardo domiciliario obligatorio sin que medie legitimación en su proceder.

Finalmente, resulta necesario precisar que el Estado mexicano no ha decretado el uso de la fuerza pública contra la población o el establecimiento de un Estado de excepción como medida de control social para atender la pandemia de Covid-19, sin embargo, debe hacer cesar los excesos en que incurren los gobernadores y alcaldes en virtud del espíritu garantista proclamado por la Constitución Política de los Estados Unidos Mexicanos y los tratados internacionales en materia de derechos humanos. 


\section{Fuentes de consulta}

CIDH. (1987). Opinión consultiva OC-8/87 del 30 de enero de 1987. El habeas corpus bajo suspensión de garantías (Arts. 27.2, 25.1 y 7.6 de la Convención Americana sobre Derechos Humanos). San José de Costa Rica: CIDH. Recuperado de https://www.corteidh.or.cr/docs/opiniones/seriea_08_esp.pdf

Código Penal de Yucatán.

Comité Nacional para la Vigilancia Epidemiológica. (2020). Aviso Epidemiológico CONAVE 109/ 2020/COVID-19 del 6 de abril de 2020. México: Comité Nacional para la Vigilancia Epidemiológica. Recuperado de https://www.gob.mx/cms/uploads/attachment/file/545445/AE_Enfermedad_COVI D-19_SARS-CoV-2_2020.04.06.pdf

Consejo General del Instituto Nacional Electoral. (2020). ACUERDO del Consejo General del Instituto Nacional Electoral por el que se determina como medida extraordinaria la suspensión de plazos inherentes a las actividades de la función electoral, con motivo de la contingencia sanitaria derivada de la pandemia del coronavirus, COVID-19. México: Diario Oficial de la Federación. Recuperado de http://www.dof.gob.mx/nota_detalle.php?codigo=5590949\&fecha=01/04/2020\&p rint=true

Constitución Política de los Estados Unidos Mexicanos.

Contreras, López, R. E. (2011). Lecciones de Derecho Penal. 2a ed. México: Códice.

Convención Americana sobre Derechos Humanos. (22 de noviembre de 1969). OEA. "Pacto San José de Costa Rica". San José de Costa Rica.

Declaración Universal de los Derechos Humanos (10 de diciembre de 1948).

Gobierno Constitucional del Estado de Michoacán de Ocampo. (2020). Decreto por el que se declara el aislamiento obligatorio ante la pandemia del virus SARS-COV-2 (Covid19). Periódico Oficial del Gobierno Constitucional del Estado de Michoacán de Ocampo. 20 de abril de 2020. Tomo CLXXIV. México. Recuperado de http://www.periodicooficial.michoacan.gob.mx/download/2020/abril/20/7a9320.pdf.pdf 
Gobierno de México. (2020). Lineamiento general para la mitigación y prevención de COVID19 en espacios públicos abiertos. México: Gobierno de México. Recuperado de https://coronavirus.gob.mx/wpcontent/uploads/2020/04/Lineamiento_Espacios_Abiertos_07042020.pdf

Gobierno del Estado de Jalisco. (2020). Acuerdo del Ciudadano Gobernador Constitucional del Estado Libre y Soberano de Jalisco, mediante el cual se emiten diversas medidas de seguridad sanitaria para el aislamiento social, de carácter general y obligatorio, con motivo de la pandemia Covid-19. El Estado de Jalisco. Periódico Oficial. 19 de abril de 2020. Tomo CCCXCVII. México. Recuperado de https://periodicooficial.jalisco.gob.mx/sites/periodicooficial.jalisco.gob.mx/files/04 -19-20-bis.pdf

Guevara Rosas, E. (2020). El falso dilema entre los derechos humanos y el control del COVID$19 . \quad$ México. Recuperado de https://www.amnesty.org/es/latest/news/2020/04/falso-dilema-entre-derechoshumanos-y-control-covid19/

Human Right Watch. (2020). Dimensiones de derechos humanos en la respuesta al COVID19. New York. Recuperado de https://www.hrw.org/es/news/2020/03/31/dimensiones-de-derechos-humanosen-la-respuesta-al-covid-19

Horcajada, J. P. y Padilla, B. (2013). Endemia y epidemia. Investigación de un brote epidémico nosocomial. En Enfermedades infecciosas y microbiología clínica. Vol. 31. Núm. $\quad 3 . \quad$ Pp. 181-186. Recuperado de https://www.seimc.org/contenidos/documentoscientificos/eimc/seimc_eimc_v31 n03p181a186.pdf

Martínez Soria, J.; Torres Ramírez, M. C.; y, Orozco Rivera, E. D. (2020). Documento de trabajo. Características, medidas de política pública y riesgos de la pandemia del Covid-19. México: Instituto Belisario Domínguez del Senado de la República. Pp. 123.

Recuperado de http://bibliodigitalibd.senado.gob.mx/bitstream/handle/123456789/4816/Covid19 \%20\%28doc\%20de\%20trabajo\%29.pdf?sequence=1\&isAllowed=y

Organización Mundial de la Salud. (2010). ¿Qué es una epidemia? Recuperado de https://www.who.int/csr/disease/swineflu/frequently_asked_questions/pandemic les/ 
Organización Mundial de la Salud. (2020). COVID-19: cronología de la actuación de la OMS. Recuperado de https://www.who.int/es/news-room/detail/27-04-2020-whotimeline---covid-19

Organización Mundial de la Salud. (a). (2020). Preguntas y respuestas sobre la enfermedad por coronavirus (COVID-19). Recuperado de https://www.who.int/es/emergencies/diseases/novel-coronavirus-2019/advicefor-public/q-a-coronaviruses

Pacto Internacional de Derechos Económicos, Sociales y Culturales. (16 de diciembre de 1966). ONU. Nueva York. E.U.A.

Pacto Internacional de Derechos Civiles y Políticos. (16 de diciembre de 1966). ONU. Nueva York. E.U.A.

Presidencia de la República. (2020). Versión estenográfica. Conferencia de prensa. Informe diario sobre coronavirus COVID-19 en México del 4 de mayo de 2020. México: Presidencia de la República. Recuperado de https://www.gob.mx/presidencia/articulos/version-estenografica-conferencia-deprensa-informe-diario-sobre-coronavirus-covid-19-en-mexico-241579?idiom=es

Principios de Siracusa sobre las disposiciones de limitación y derogación del Pacto Internacional de Derechos Civiles y Políticos- Naciones Unidas. Nueva York. 24 de agosto de 1984.

Protocolo adicional a la Convención Americana sobre Derechos Humanos en materia de Derechos Económicos, Sociales y Culturales "Protocolo de San Salvador".

Salazar Ugarte, P. (2013). “Estado de excepción, suspensión de derechos y jurisdicción”. En Ferrer McGregor, E.; Caballero Ochoa, J. L.; y, Steiner, C. (Coords.). Derechos humanos en la Constitución. Comentarios de jurisprudencia constitucional e interamericana. México: UNAM, SCJN, Konrad Adenauer Stiftung. Pp. 231-257. Recuperado de https://archivos.juridicas.unam.mx/www/bjv/libros/8/3567/13.pdf

Secretaría de Salud. (2020). Comunicado Técnico Diario Covid-19. 2020.05.30. México: Secretaría de Salud. Pp. 1-2. Recuperado de https://www.gob.mx/cms/uploads/attachment/file/554970/Comunicado_Tecnico _Diario_COVID-19_2020.05.30.pdf

Secretaría de Salud. (a). (2020). Comunicado Técnico Diario Covid-19. 2020.03.14. México: Secretaría de Salud. Pp. 1-2. Recuperado de 
https://www.gob.mx/cms/uploads/attachment/file/541491/Comunicado_Tecnico _Diario_COVID-19_2020.03.14.pdf

Secretaría de Salud. (b). (2020). ACUERDO por el que se establecen las medidas preventivas que se deberán implementar para la mitigación y control de los riesgos para la salud que implica la enfermedad por el virus SARS-CoV2 (COVID-19). México: Diario Oficial de la Federación. Recuperado de https://www.dof.gob.mx/nota_detalle.php?codigo=5590339\&fecha=24/03/2020

Secretaría de Salud. (c). (2020). Inicia la fase 3 por COVID-19. México: Secretaría de Salud. Recuperado de https://www.gob.mx/salud/prensa/110-inicia-la-fase-3-por-covid19

Secretaría de Salud. (d). (2020). ACUERDO por el que se establece una estrategia para la reapertura de las actividades sociales, educativas y económicas, así como un sistema de semáforo por regiones para evaluar semanalmente el riesgo epidemiológico relacionado con la reapertura de actividades en cada entidad federativa, así como se establecen acciones extraordinarias. México: Diario Oficial de la Federación. Recuperado de www.dof.gob.mx/nota_detalle.php?codigo=5593313\&fecha=14/05/2020

Secretaría de Salud. (e). (2020). ACUERDO por el que se establecen los Lineamientos Técnicos Específicos para la Reapertura de las Actividades Económicas. México: Diario Oficial de la Federación. Recuperado de https://www.dof.gob.mx/nota_detalle.php?codigo=5594138\&fecha=29/05/2020

Secretaría de Educación Pública. (2020). ACUERDO número 02/03/20 por el que se suspenden las clases en las escuelas de educación preescolar, primaria, secundaria, normal y demás para la formación de maestros de educación básica del Sistema Educativo Nacional, así como aquellas de los tipos medio superior y superior dependientes de la Secretaría de Educación Pública. México: Diario Oficial de la Federación. Recuperado de https://www.dof.gob.mx/nota_detalle.php?codigo=5589479\&fecha=16/03/2020

Subsecretaria de Derechos Humanos, Población y Migración. (2020). Observaciones sobre Violaciones a Derechos Humanos durante la Contingencia Sanitaria por COVID-19. México: Secretaría de Gobernación. Pp. 1-18. Recuperado de https://www.gob.mx/cms/uploads/attachment/file/549001/OBSERVACIONES_SOB RE_VIOLACIONES_A_DERECHOS_HUMANOS_DURANTE_LA_CONTINGENCIA_SANIT ARIA_POR_COVID-19_2_.pdf 
Suprema Corte de Justicia de la Nación. (1924). Derecho de tránsito. Tesis s/n. Pleno. Quinta Época. Tomo XIV. México: Suprema Corte de Justicia de la Nación.

Suprema Corte de Justicia de la Nación. (2013). Derechos humanos. Requisitos para restringirlos o suspenderlos conforme a los artículos $1^{\circ}$ de la Constitución Política de los Estados Unidos Mexicanos y 30 de la Convención Americana sobre Derechos Humanos. Tesis 1a. CCXV/2013 (10a.). Primera Sala. Décima Época. Libro XXII. Julio de 2013. Tomo 1. México: Suprema Corte de Justicia de la Nación.

Vila Dosal, M. [@MauVila]. (29 de marzo de 2020). “No permitiremos que la salud de la población yucateca se ponga en riesgo, es por eso que a la persona que presente los síntomas o haya sido diagnosticada con el Coronavirus y no acate las medidas de aislamiento para evitar el contagio, se le podrá imponer un castigo ...". 5:25 pm., [Tuit]. Twitter. https://twitter.com/MauVila/status/1244405294874099718 Recuperado el 30 de mayo de 2020.

Vila Dosal, M. (a). [@MauVila]. (29 de marzo de 2020). “... de hasta 3 años de cárcel y además podrá ser acreedora a una multa de hasta $\$ 86,800$. Esto bajo las sanciones que contemplan el Código Penal y La Ley de Salud de \#Yucatán. ¡Prevenir es tarea de todos! \#QuédateEnCasa \#UnidosComoUnoSolo (2/2)". 5:25 pm., [Tuit]. Twitter. https://twitter.com/MauVila/status/1244405297176854531 Recuperado el 30 de mayo de 2020. 